\title{
Melatonin and charged particle irradiation inhibit tumor angiogenesis
}

\author{
Liu MT ${ }^{1,2 *}$ and Reiter $\mathrm{RJ}^{3}$ \\ ${ }^{1}$ Department of Radiation Oncology, Changhua Christian Hospital, Taiwan \\ ${ }^{2}$ Department of Radiology, Yuanpei University of Science and Technology, Taiwan \\ ${ }^{3}$ Department of Cellular and Structural Biology, The University of Texas Health Science Center, USA
}

\begin{abstract}
Aim: This study was performed to evaluate the role of melatonin and carbon ion radiation on angiogenesis. Angiogenesis is the formation of new capillaries from existing vasculature and plays an essential role in the growth and dissemination of cancer.

Materials and methods: We conducted a systematic review of the existing literature by searching for keywords in PubMed (January 2000 - April 2016) using the search terms: 'melatonin', 'X-ray irradiation', 'charged particle irradiation', 'carbon ion irradiation', 'migration', 'invasion' and 'angiogenesis'. We identified reports containing the impact of melatonin and charged particle irradiation on migration, invasion and angiogenesis of tumor cells for inclusion. Reports which were published in languages other than English, only published in abstract form, not related to angiogenesis/invasion of tumor cells, or duplicate articles and those containing insufficient detail were excluded.

Results: The collected data documented the impact of melatonin and charged particle irradiation on tumor angiogenesis.

Conclusion: Since angiogenesis plays a crucial role in tumor invasion and metastasis, targeting the VEGF pathway could be highly effective strategy for targeting the spread of tumor cells. Melatonin treatment effectively attenuates VEGF levels. Hypoxia in a tumor is a fundamental cause of angiogenesis. Under hypoxic condition, melatonin inhibited HIF-1 transcriptional activity, resulting in a reduction of VEGF expression. Melatonin suppressed the stability of HIF-1 $\alpha$. Melatonin also lowered HIF-1 $\alpha$ accumulation through inhibition of sphingosine kinase 1 (SPHK1) pathway and ROS generation in PC-3 cells under hypoxia. MicroRNAs (miRNAs) play essential roles in angiogenesis. Melatonin upregulated miRNA3195 and miRNA374b. Over-expression of miRNA3195 and miRNA374b synergistically attenuates VEGF production by hypoxic PC-3 cells, indicating the critical role of miRNA3195 and miRNA374b in melatonin-induced anti-angiogenic activity. Photons upregulate pro-angiogenic factors resulting in enhanced angiogenesis and metastasis. The capillary-like tube structures are abolished after $0.1 \mathrm{~Gy}$ carbon ion irradiation. Heavy ion irradiation could be more effective than X-ray irradiation in counteracting angiogenesis even at sublethal doses. In addition to angiogenesis, cancer cell invasion and migration are fundamental aspects of cancer progression that significantly contribute to metastasis. Heavy ions decreased migration of HCT116 colon carcinoma and U87 glioma cell lines dose-dependently. Carbon beam irradiation reduces the migration and invasion capabilities of both A549 and EBC-1 cells more effectively than does photon irradiation. Carbon ion irradiation suppresses the metastatic potential of Non-Small-Cell Lung Cancer (NSCLC) cells. These results imply a potential for particle irradiation in the treatment of systemic disease. Further investigation to elucidate the mechanisms and molecular pathways involved in angiogenesis specifically associated with melatonin and charged particle irradiation is warranted.
\end{abstract}

\section{Introduction}

Angiogenesis is the formation of new capillaries from existing vasculature, characterized by endothelial cell proliferation, migration, basement membrane degeneration and new tubule formation [1,2]. New blood vessels in a tumor mass supplies oxygen and nutrients for tumor growth and provides a path for tumor cell migration and metastasis [3-5]. Angiogenesis plays an essential role in the growth and dissemination of cancer [2,6-8]. Thus, angiogenesis inhibition is a promising strategy for the treatment of cancer along with conventional therapies such as chemotherapy and radiotherapy [6].

Radiation therapy is an important modality of cancer treatment. $\mathrm{X}$-rays are widely used photons in radiation therapy. X-rays are defined as low LET (Linear Energy Transfer) radiation which produce sparse ionization along their trajectories [9]. Failure of radiation therapy using photon irradiation is commonly related with metastasis [10]. There is an increasing application of high-LET charged particles such as protons and carbon ions in the treatment of cancer [11-13]. Carbon ions generate dense ionization along their trajectories, and induce unrepairable clustered DNA damage. Carbon ions are more potent in the induction of cytogenetic damage and cytotoxicity of irradiated cells than low-LET X-rays [13,14]. Takahashi and colleagues [15] reported that X-ray irradiation enhanced the capillary-like tube structure in three-dimensional culture. On the contrary, angiogenesis was inhibited by carbon ion irradiation even at sublethal dose (0.1 Gy).

Melatonin (N-acetyl-5-methoxy-tryptamine), an indolic compound synthesized by the pineal gland and many other tissues, is an effective jktumor inhibitor [16-23]. This molecule exerts anticancer

Correspondence to: Mu-Tai Liu, Department of Radiation Oncology, Changhua Christian Hospital, 135 Nan Shiau Street, Changhua, Taiwan, Tel: +886-47238595, Fax: +886-4-7232942; E-mail: tomgiessen@gmail.com

Key words: melatonin, $x$-ray irradiation, charged particle irradiation, carbon ion irradiation, migration, invasion, angiogenesis

Received: August 30, 2016; Accepted: September 28, 2016; Published: October 03,2016 
effects in numerous types of cancer, due to its pro-apoptotic, antiproliferative, anti-cell differentiation and anti-angiogenic actions [24,25]. Also, while melatonin is a well-established antioxidant in normal cells, it is strongly pro-oxidant in cancer cells and aids in killing them [25-28]. Hypoxia of the tumor is an essential cause of angiogenesis [29]. Several publications documented that melatonin inhibited angiogenesis [30-32]. Under hypoxic conditions, melatonin inhibits Hypoxia Inducible Factor 1 (HIF-1) transcriptional activity, resulting in suppression of VEGF expression [33]. HIF-1 $\alpha$ is stabilized by Reactive Oxygen Species (ROS) caused by hypoxia and increases the expression of the angiogenic activators, such as VEGF. VEGF is the most important endogenous pro-angiogenic factor, which brings about angiogenesis by directly acting on the endothelium [34]. Several studies verify that melatonin downregulates the expression of HIF-1a and VEGF in a variety of tumors [33-36].

Endothelial cells are also influenced by melatonin. The study of Alvarez-Garcia and colleagues showed that melatonin markedly inhibited growth and tube formation by endothelial cells [37]. Human Umbilical Vein Endothelial Cells (HUVECs) exhibited an increased cell proliferation and cell migration when co-cultured with Pancreatic Carcinoma Cells (PANC-1) cells; this process was suppressed with the addition of melatonin to the incubation medium [38]. Melatonin at pharmacological concentrations inhibits cell proliferation and migration of HUVECs co-cultured with PANC-1 cells. These observations correlate with the inhibition of the VEGF protein secreted to the cultured medium and the VEGF protein produced by the PANC-1 cells [35]. Moreover, melatonin plays a role in the paracrine interactions between malignant breast epithelial cells and endothelial cells through downregulation of VEGF leading to the reduction of tumor angiogenesis [39]. A thorough understanding of the mechanisms and molecular pathways activated in angiogenesis is essential in identifying novel treatment options for cancer therapy that target angiogenesis.

\section{Materials and methods}

\section{Literature search strategy}

A systematic review of the existing literature was conducted using the following search terms: 'melatonin', 'X-ray irradiation', 'charged particle irradiation', 'carbon ion irradiation', 'migration', 'invasion' and 'angiogenesis'. The search used PubMed and spanned the period from January 2000 to April 2016.

\section{Inclusion and exclusion criteria}

We identified reports containing the impact of melatonin and charged particle irradiation on migration, invasion and angiogenesis of tumor cells for inclusion. Reports which were published in languages other than English, only published in abstract form, not related to angiogenesis/invasion of tumor cells, duplicate articles and containing insufficient detail were excluded. All titles and abstracts were screened to assess whether they were eligible for inclusion. Then abstracts and full texts of all eligible studies were evaluated and data was evaluated.

\section{Results}

\section{Literature search results}

The search identified 551 potentially eligible articles. After application of the exclusion criteria, 63 reports were eligible. The collected data included the impact of melatonin and charged particle irradiation on tumor angiogenesis. The impact of melatonin on angiogenesis consisted of 'Melatonin suppresses tumor angiogenesis by inhibiting VEGF', 'Melatonin suppresses tumor progression by reducing angiogenesis induced by HIF-1', 'Antiangiogenic effects of melatonin on endothelial cells' and 'Upregulation of microRNAs mediates the anti-angiogenic properties of melatonin'. The impact of charged particle irradiation on tumor angiogenesis consisted of 'Heavy ion irradiation inhibits angiogenesis', 'Comparison of the effects of carbon ion and photon irradiation on the angiogenic response in human lung adenocarcinoma cells', 'Carbon ion radiation may inhibit angiogenesis of glioblastoma' and 'Proton irradiation suppresses angiogenic genes and impairs cell invasion and tumor growth'.

\section{Melatonin suppresses tumor angiogenesis by inhibiting VEGF}

Regulation of VEGF by melatonin in human breast cancer cells: To investigate the role of melatonin on the regulation of VEGF in breast cancer cells, Alvarez-Garcia and colleagues [39] co-cultured human breast cancer cells (MCF-7) with HUVECs. Incorporation of VEGF into the cultures stimulated the proliferation of HUVECs. One $\mathrm{mM}$ melatonin inhibited this effect. Melatonin reduced VEGF production as well as VEGF mRNA expression in MCF-7 cells. MCF-7 cells co-cultured with HUVECs activated proliferation of endothelial cells, while it enhanced VEGF levels in the culture media. Melatonin inhibited both HUVECs proliferation and VEGF protein levels in the co-culture media. Conditioned media from MCF-7 cell culture stimulated HUVECs proliferation, which was significantly inhibited by anti-VEGF or $1 \mathrm{mM}$ melatonin. These findings imply that melatonin may play a role in the paracrine interactions between malignant epithelial cells and proximal endothelial cells through a downregulatory action on VEGF expression in human breast cancer cells; this results in a reduction of the level of VEGF around endothelial cells. Decreased levels of VEGF could be critical in reducing the number of estrogenproducing cells proximal to malignant cells while reducing tumor angiogenesis [39].

The anti-angiogenic effect of melatonin in liver cancer cells via suppressing VEGF expression: Hepatocellular Carcinoma (HCC) is regarded as a hypervascular tumor, and angiogenesis has a critical role in HCC development and progression [40-42]. VEGF is commonly overexpressed in HCC tissues, which is generally related with tumor size and histologic grade [43-45]. Sun and colleagues reported that increased VEGF expression correlated with tumor progression, microvessel invasion and metastasis of HCC [46]. Signal transducer and activator of transcription 3 (STAT3) and HIF-1a were associated in mediating VEGF transcription [47,48]. Carbajo-Pescador and colleagues reported that administration of melatonin lowered VEGF secretion by HepG2 cells [23]. A hypoxia-dependent activation of VEGF transcriptional regulators, HIF-1 $\alpha$ and phospho-STAT3, were also inhibited by melatonin at the pharmacologic concentration $(1 \mathrm{mmol} / \mathrm{L})$ [23]. The authors proposed that anti-angiogenic effect of melatonin was due to its capability to prevent STAT3 activation, which generally increased HIF-1a stability and enhanced its transcriptional activity. Further investigations to assess the effectiveness of melatonin for the prevention and treatment of liver cancer are necessary.

Melatonin inhibits the expression of VEGF in pancreatic cancer cells: Pancreatic carcinoma is characterized by abundant tumor neoangiogenesis and extensive vascularization in association with the overexpression of several angiogenic factors including VEGF, plateletderived endothelial cell growth factor, and matrix metalloproteinases [49-51]. VEGF is a secreted mediator involved in the extracellular 
environment $[35,49]$. VEGF is detected in the cytoplasm of tumor cell by the immunocytochemical staining [52].

The study of Lv and colleagues demonstrated that high melatonin concentrations significantly suppressed Pancreatic Carcinoma Cells (PANC-1) proliferation, with $1 \mathrm{mmol} / \mathrm{L}$ concentration exhibiting the maximal inhibitory effect [52]. VEGF concentrations in the cell culture supernatants and cytoplasm were reduced after incubation with 1 $\mathrm{mmol} / \mathrm{L}$ melatonin. VEGF mRNA expression decreased obviously during the observation period [52]. Melatonin has potential as a novel effective anti-angiogenesis therapy of cancer.

Molecular markers of angiogenesis and metastasis in lines of oral carcinoma after treatment with melatonin: The local invasion, metastasis in cervical lymph nodes and distant metastases to other organs contribute to the poor prognosis of oral carcinoma [53-55]. The high mortality and morbidity rate of oral cancer is closely correlated to the processes of angiogenesis and tumor metastasis [56-58]. The overexpression of the pro-angiogenic genes, HIF-1 $\alpha$ and VEGF, and pro-metastatic gene, ROCK-1, are associated with unfavorable outcome of oral carcinoma [59,60]. Goncalves Ndo and colleagues reported that SCC9 cells (squamous cell carcinoma of the tongue) treated with melatonin under hypoxia demonstrated decreased expression of HIF$1 \alpha$ and VEGF gene, when compared to untreated cells under hypoxia [60]. Using immunocytochemistry followed by the quantification of immunostaining by optical densitometry, SCC 9 cells treated with melatonin under hypoxia exhibited a decrease in immunostaining of HIF-1 $\alpha$ and VEGF [60]. Further investigation to verify the potential therapeutic effect of melatonin in other subtypes of oral carcinoma is warranted.

\section{Melatonin suppresses tumor progression by reducing angiogenesis induced by HIF-1}

Effect of melatonin on angiogenesis induced by HIF-1 $\alpha$ in breast cancer: Hypoxia sets off a series of events leading to angiogenesis and tumor progression when the tumor size is approaching a few millimeters [61,62]. Hypoxia induces expression of VEGF as well

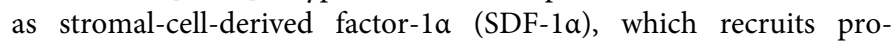
angiogenic cells from the bone marrow [63-67]. Some works suggested that the pharmacological concentration of melatonin may inhibit angiogenesis both directly and indirectly $[31,33,68,69]$. Several studies demonstrated that melatonin downregulated the expression of hypoxia inducible factor 1 alpha (HIF-1 $\alpha$ ) and VEGF in a variety of tumors [33,61,69-71]. Melatonin possesses anticancer effects in many tumor types. This inhibition involves an uncommonly large number of different actions mediated by melatonin [72-80]. A study by JardimPerassi and colleagues specifically mentioned that melatonin treatment was effective in inhibiting ER-negative mammary tumor angiogenesis, which was indicated by the reduction of VEGFR2 expression [81].

As already noted, hypoxia in a tumor is an essential cause of angiogenesis [29,82]. Hypoxia allows stabilization of HIF-1a, resulting in increased VEGF-A transcription, which binds to VEGFR2 [81]. Serum VEGF levels reported decrease after administration of melatonin when rats are exposed to hypoxia. This finding suggests that melatonin reduced hypoxic adaptation of tumor cells through inhibition of angiogenesis $[32,83]$. Jardim-Perassi and colleagues demonstrated that melatonin inhibited tumor growth, cell proliferation and angiogenesis in breast cancer. There is no essential systemic toxicity related to melatonin treatment $[79,81,84]$. This emphasizes the importance of its usefulness as an oncostatic agent either alone or in combination with conventional chemotherapeutics [85-88].
Melatonin suppresses tumor angiogenesis by inhibiting HIF1a stabilization under hypoxia: HIF-1 $\alpha$ is the essential transcription factor involved in regulation of angiogenesis in cancer. HIF-1a is stabilized by Reactive Oxygen Species (ROS) caused by hypoxia and increases the expression of the angiogenic activators, such as VEGF. Park and colleagues found that melatonin destabilized hypoxia-induced HIF-1a protein levels in the HCT116 human colon cancer cell line [89]. This destabilization of HIF-1a derived from the antioxidant activity of melatonin against ROS was associated with hypoxia. Under hypoxic conditions, melatonin inhibited HIF-1 transcriptional activity, leading to inhibition of VEGF expression. Melatonin suppressed in vitro tube formation, invasion and migration of HUVECs induced by hypoxiastimulated conditioned media of HCT116 cells. These findings imply that melatonin could play a crucial role in tumor suppression through inhibition of HIF-1-mediated angiogenesis [89].

Melatonin suppresses tumor progression by reducing angiogenesis stimulated by HIF-1: Hypoxia found in the tumor is a crucial cause of angiogenesis, which is an essential factor of tumor progression [90]. HIF-1 $\alpha$ is an essential transcription factor related to the hypoxic response of cancer cells. It initiates transcription of genes controlling angiogenesis, proliferation, invasion and metastasis in cancer [91].

A study of Kim and colleagues demonstrated that the administration of melatonin inhibited tumor angiogenesis in RENCA cell (renal adenocarcinoma) mouse tumor model [29]. Melatonin reduced the expression of the HIF-1a protein in the tumor during tumorigenesis. These findings are consistent with melatonin being a promising antiangiogenic therapeutic agent targeting HIF-1 $\alpha$ in cancer. Reiter and colleagues mentioned that the side effects of melatonin are negligible over a very large dose range. Moreover, it can be administered via any route over long periods [92]. These findings suggest that melatonin could be an effective therapeutic agent for acute or long-term melatonin treatment.

Sphingosine kinase 1 pathway in melatonin-induced HIF-1a inactivation: Sphingosine Kinase 1 (SPHK1) is a regulator of HIF-1a with different biological activities such as induction of angiogenesis, cell growth and invasion. SPHK1 activity is increased in various types of cancer. Cho and colleagues demonstrated that hypoxia increased SPHK1 activity as well as HIF-1 $\alpha$ accumulation compared with those levels under normoxic conditions [93]. Melatonin at $1 \mathrm{mmol}$ (a pharmacological concentration) reduced SPHK1 activity to $70 \%$ under hypoxia compared with control values. SPHK1 activity was persistently reduced in melatonin-treated cells under hypoxia. Melatonin also suppressed HIF-1 $\alpha$ accumulation in a dose-dependent manner in PC-3 cells under hypoxia.

To confirm the role of SPHK1 in melatonin mediated AKT/GSK$3 \mathrm{~b}$ signaling inhibition under hypoxia, a SPHK1 siRNA assay was utilized in PC-3 cells subjected to hypoxia. SPHK1 siRNA transfection enhanced the inhibitory effects of melatonin on HIF-1 $\alpha$ accumulation and the phosphorylation of AKT in PC-3 cells under these conditions. Reactive Oxygen Species (ROS) scavengers such as N- acetylcysteine inhibited HIF-1 $\alpha$ by means of blocking SPHK1 activity under hypoxia. The treatment with either melatonin or $\mathrm{N}$ - acetylcysteine reduced hypoxia-mediated HIF-1 $\alpha$ expression and SPHK1 activity. Additionally, combined treatment with melatonin and $\mathrm{N}$ - acetylcysteine inhibited both HIF-1a expression and SPHK1 activity to $38 \%$ of those in untreated control. These findings indicate that melatonin attenuates hypoxia-induced HIF-1 $\alpha$ accumulation and SPHK1 activation through 
inhibition of ROS-related pathway in hypoxic PC-3 cells as a potential anti-cancer agent for prostate cancer therapy [93].

Melatonin modulates the expression of VEGF and HIF-1a induced by $\mathrm{CoCl} 2$ in cultured cancer cells: To assess the impact of melatonin on angiogenesis, Dai and colleagues utilized three human cancer cell lines (PANC-1, HeLa and A549 cells) to study the effect of melatonin on endogenous VEGF expression in these cell lines [35]. The high cobalt chloride induced levels of VEGF mRNA were attenuated significantly by $1 \mathrm{mmol}$ melatonin. The levels of VEGF protein were markedly reduced in the melatonin-treated cells compared with that of the control cells. Melatonin may suppress the VEGF expression through the inhibition of the accumulation of HIF-1 $\alpha$ [35]. Furthermore, $1 \mathrm{mmol}$ melatonin significantly reduced $\mathrm{CoCl} 2$-induced HIF-1 $\alpha$ protein levels in three cell types tested. These findings demonstrate that melatonin markedly inhibits the expression of endogenous VEGF and HIF-1 $\alpha$ induced by cobalt chloride in cancer cell lines. Melatonin clearly may be a potential novel agent in challenging antiangiogenesis therapy of cancer.

\section{Antiangiogenic effects of melatonin on endothelial cells}

Antiangiogenic effects of melatonin in endothelial cell cultures: Endothelial cells play an essential role in the development and progression of cancer through controlling angiogenesis [37]. VEGF is the most important endogenous pro-angiogenic factor, which brings about angiogenesis by directly acting on the endothelium [34]. Alvarez-Garcia and colleagues indicated that melatonin might play a role in the paracrine interactions between malignant epithelial cells and proximal endothelial cells through downregulation of VEGF expression in human breast cancer cells; melatonin decreases the levels of VEGF around endothelial cells [37]. Cui and colleagues noted that 1 mmol melatonin added to the cultures medium suppressed the growth of HUVECs, while Alvarez-Garcia et al. reported that melatonin inhibited proliferation of HUVECs. Melatonin treatment for 5 and 8 hours suppressed the distance migrated by HUVECs by $30 \%$ and $32 \%$ respectively, in comparison to untreated cells [30,37]. Melatonin caused a $30 \%$ decline in the number of HUVECs that invaded through the basement membrane in response to VEGF [37]. Melatonin also disrupted tube formation and the reduced average tube length by approximately $40 \%$. Conditioned media obtained from human breast cancer cells possessed angiogenic activity and caused tubule length formation. This effect was attenuated by the addition of melatonin. Furthermore, melatonin caused the disintegration of preformed capillary networks. The antiangiogenic effect of melatonin could be an important factor in breast cancer inhibition.

Melatonin prevents HUVEC proliferation and migration by inhibiting VEGF expression: Pancreatic cancer is a highly vascularized and angiogenic solid tumors which responds poorly to chemotherapy and radiation. Cui and colleagues found HUVECs exhibited increased cell proliferation and cell migration when co-cultured with pancreatic carcinoma cells (PANC-1) cells [38]. The activity was suppressed by the addition of melatonin into the incubation medium. Melatonin inhibited cell proliferation and migration of HUVECs co-cultured with PANC-1 cells. This process was accompanied by inhibition of the VEGF protein secreted into the cultured medium as well as a drop in VEGF protein produced by the PANC-1 cells. Furthermore, melatonin downregulated the VEGF mRNA expression [38]. Thus, pancreatic cancer which is uncommonly difficult to treat, may respond to melatonin because of its anti-angiogenic activity [94].

Melatonin suppresses migration of HUVECs via inhibition of
ERK/Racl activation: HIF-1a translocates into the nucleus under hypoxic conditions. It upregulates the transcription of its target genes, including Matrix Metalloproteinases (MMPs) and VEGF, which relate to the migration of endothelial cells and angiogenesis [95,96]. Rac1, a member of the Rho GTPases family, is an essential regulator of cell migration [97]. Yang and colleagues showed that the anti-Racl effect of melatonin in HUVECs related to its inhibition of ERK [97]. They found that melatonin reduced hypoxia-stimulated HIF-1a expression and endothelial cell migration, critical steps in angiogenesis. Under hypoxic condition, melatonin decreased Racl activation and inhibited the co-localized Racl and F-actin on the membrane of HUVECs. Furthermore, inhibition of Racl activation with ectopic expression of an inactive mutant form of Rac1-T17N decreased HIF-1a expression and cell migration in response to hypoxia. These findings show that melatonin is capable of suppressing ERK/Racl activation and interrupts the stabilization of HIF- $1 \alpha$, resulting in a notable inhibition of the migration and angiogenesis of hypoxic HUVECs [97].

Upregulation of miRNA3195 and miRNA374b mediates the anti-angiogenic properties of melatonin: MicroRNAs (miRNAs), consisting of non-coding small RNAs ( 20-22 nt) and single-stranded RNA molecules, commonly regulate gene expression at the posttranscriptional level and play critical roles in cell growth, autophagy and angiogenesis [98-100]. To investigate whether melatonin influences angiogenesis by regulating miRNAs, Sohn and coworkers [101] employed miRNA array to identify miRNA profiles in melatonintreated PC-3 cells under hypoxia. miRNA array analysis demonstrated that miRNA3195 and miRNA 374b were upregulated in melatonintreated PC-3 cells under hypoxia compared to untreated conditions. Quantitative real-time PCR assay (qRT-PCR) showed that the levels of miRNA3195 and miRNA374b were upregulated in melatonin-treated PC-3 cells under hypoxia in contrast to hypoxia only [101]. Also, melatonin reduced the expression of HIF-1 $\alpha$ and VEGF at mRNA level in hypoxic PC-3 cells. Melatonin attenuated VEGF production in hypoxic PC-3 cells transfected with miRNA3195 and miRNA374b mimics compared to miRNA vector control or only melatonin treated controls. These findings indicate that upregulation of miRNA3195 and miRNA374b may be an essential role in anti-angiogenic activity induced by melatonin in hypoxic PC-3 cells [101].

\section{The impact of charged particle irradiation on tumor angiogenesis}

Heavy ion irradiation inhibits angiogenesis: In the study of Takahashi et al., ECV304 cell line obtained from American Type Culture Collection and HUVECs were exposed to carbon ion beams with energy of $290 \mathrm{MeV}$ (linear energy transfer $110 \mathrm{keV} / \mu \mathrm{m}$ ) or $4 \mathrm{MV}$ $\mathrm{X}$-rays (linear energy transfer $1 \mathrm{keV} / \mu \mathrm{m}$ ) [15]. The capillary like tube structures were abolished after 0.1 Gy carbon ion irradiation. Matrix metalloproteinase- 2 activity and migration to vitronectin were also inhibited by carbon ion irradiation. On the contrary, X-ray irradiation enhanced the capillary-like tube structure after $>8 \mathrm{~Gy}$ irradiation. These findings implied that heavy ion irradiation could be more effective than $\mathrm{X}$-ray irradiation in counteracting angiogenesis even at a sublethal dose.

Comparison of the effects of carbon ion and photon irradiation on the angiogenic response in human lung adenocarcinoma cells: $\mathrm{X}$-rays are reported to promote angiogenesis and increase metastasis by enhancing the expression of pro-angiogenic factors such as VEGF, stem cell factor (SCF), HIF-1 $\alpha$, basic Fibroblast Growth Factor (bFGF), and Placenta-Like Growth Factor (PlGF) secreted by tumor cells [102- 
105]. Human lung adenocarcinoma (A549) cells were utilized in an experiment conducted by Kamlah et al. to compare the effects of carbon ion and X-ray irradiation on the angiogenic response of tumor cells [105]. The A549 cells were irradiated with biologically equivalent doses of either carbon ions ( $2 \mathrm{~Gy}$; linear energy transfer, $170 \mathrm{keV} / \mathrm{mm}$; energy of $9.8 \mathrm{MeV} / \mu$ on target) or X-rays (8 Gy). A549 cells exposed to X-rays resulted in an increase in tumor angiogenesis which was probably mediated by X-ray-dependent induction and secretion of Stem Cell Factor (SCF) in A549 cells. In contrast, carbon ion radiation inhibited angiogenesis involving both tumor cells and endothelial cells even at a sublethal dose. With respect to the treatment of lung adenocarcinoma, carbon ion irradiation may represent a more effective therapy than that of X-ray irradiation $[15,105,106]$.

Effects of carbon-ion beam irradiation on the angiogenic response in lung adenocarcinoma cells: Liu and colleagues investigated the expression of VEGF and bFGF in the Tumor Conditioned Medium (TCM) of A549 cells [107]. A549 cells exposed to carbon-ion or X-ray irradiation were cultured with serum-free MCDB131 medium. X-ray irradiation at 2 and 4 Gy enhanced the secretion of VEGF in A549 cells. Carbon-ion irradiation at $1 \mathrm{~Gy}$ suppressed VEGF and bFGF level. Using a transwell chamber assay, the TCM of A549 cells exposed to carbonion irradiation at $1 \mathrm{~Gy}$ markedly reduced the number of invasive cells. The TCM of cells irradiated with X-rays notably enhanced the invasion of Human Microvascular Endothelial Cells (HMEC-1) [104]. With respect to capillary-like tube formation, the TCM of A549 cells exposed to X-ray irradiation caused a substantial enhancement in the formation of capillary-like structures in HMEC-1 cells. On the contrary, the TCM of A549 cells exposed to carbon-ion irradiation at 1 Gy substantially suppressed capillary formation. These data imply that carbon-ion irradiation at $1 \mathrm{~Gy}$ inhibits the process of angiogenesis by decreasing endothelial cell invasion and tube formation.

Carbon ion radiation inhibits angiogenesis of glioblastoma: Liu et al. also reported that C6 glioma and human microvascular endothelial cells exposed to photon radiation-conditioned medium induced a dose-dependent enhancement of tube formation and cell migration with an upregulation of VEGF expression [108]. Conditioned media from C6 glioma cells irradiated with 4.0 Gy carbon ion beam inhibited the formation of endothelial cell tubules, suggesting that heavy ion irradiation suppressed the process of angiogenesis. VEGF secretion was reduced at $4.0 \mathrm{~Gy}$ carbon ion irradiation. Through modulation of VEGF production and release into the tumor microenvironment, carbon ion irradiation likely reduces angiogenesis of glioblastoma.

Proton irradiation suppresses angiogenic genes and impairs cell invasion and tumor growth: When Human Microvascular Endothelial Cells of lung (HMVEC) and human lung adenocarcinoma (A549) cells were exposed to photon irradiation, the expression of VEGF, IL-8, HIF-1 $\alpha$, and IL-6 were upregulated in a dose-dependent manner relative to control levels ( $0 \mathrm{~Gy}$ ) $6 \mathrm{~h}$ after irradiation. Girdhani and coworkers showed that proton irradiation decreased expression of pro-angiogenic factors and multiple angiogenesis-associated processes, including invasion and endothelial cell proliferation [109]. Dose-dependent inhibition of angiogenic signaling was detected in human lung adenocarcinoma cells, mouse lung carcinoma (LLC) cells, HMVEC and Normal Human Dermal Fibroblasts (NHDF). Genomewide array analysis and real-time quantitative RT-PCR demonstrated that angiogenic genes, including VEGF and HIF- $1 \alpha$, were significantly downregulated after proton irradiation (0.5, 1.0 and $2.0 \mathrm{~Gy})$.

Endothelial cell proliferation and invasion were inhibited by culturing them with irradiated A549 adenocarcinoma or fibroblast cells. This finding supports the idea that proton irradiation may contribute to inhibition of angiogenesis. Proton irradiation may inhibit processes of tumor progression (e.g., invasion, migration and angiogenesis) necessary for metastasis. Thus, proton irradiation may counteract the dissemination of cancer cells.

\section{Discussion}

Angiogenesis is a fundamental process involved in tumor invasion and metastasis [110]. This complex process constitutes a critical point of control of cancer progression [111]. Numerous studies suggested that suppression of the VEGF pathway may be even more effective strategy than targeting the tumor itself, based on the fact that angiogenesis is a major characteristic of solid tumors, regardless their etiological origin [112-114]. Furthermore, often it is the cancer metastases that contribute to morbidity rather than the primary tumor. VEGF produced by tumor cells is necessary for the progression of breast cancer, presumably by increasing proliferation of endothelial cells from neighboring blood vessels [39]. MCF-7 cells co-cultured with HUVECs activate the proliferation of endothelial cells and enhanced VEGF levels in the culture media. Melatonin inhibited both HUVEC proliferation and VEGF protein levels in the culture medium. Pancreatic carcinoma is characterized by ample tumor neoangiogenesis in association with the overexpression of VEGF [49-51]. High melatonin concentrations suppressed Pancreatic Carcinoma Cell (PANC-1) proliferation, particularly when the melatonin concentration reached $1 \mathrm{mmol} / \mathrm{L}$ [49]. VEGF concentrations in the cell culture supernatants and cytoplasm were reduced after incubation with $1 \mathrm{mmol} / \mathrm{L}$ of melatonin. CarbajoPescador and colleagues [23] demonstrated that melatonin treatment effectively attenuated VEGF levels, mainly at the pharmacological dose, and decreased VEGF secretion by HepG2 cells. HUVECs cultured with conditioned medium from the melatonin treated group were incapable of presenting its endothelial features. Cui et al. reported that melatonin suppressed human pancreatic carcinoma cell PANC1-induced HUVEC proliferation and migration by inhibiting VEGF expression [38]. In spite of the fact that VEGF expression is influenced by many factors, hypoxia appears to be the principal regulator of its production $[115,116]$. HIF- $1 \alpha$ is the basic transcription factor involved in regulation of angiogenesis in cancer [33]. Melatonin suppressed the stability of HIF-1a. Furthermore, melatonin attenuated sphingosine kinase 1 (SPHK1) activity in PC-3 cells during hypoxia [93]. SPHK1 is a regulator of HIF-1a with different biological activities such as angiogenesis and invasion. Melatonin suppresses HIF- $1 \alpha$ accumulation through inhibition of SPHK1 pathway and ROS generation in PC-3 cells under hypoxia.

Some studies revealed that microRNAs (miRNAs) play essential roles in angiogenesis $[117,118]$. The hypoxia-regulated microRNAs (miRNAs), miRNA-15b, miRNA-16b and miRNA-20a/b, are recognized to control VEGF production $[119,120]$. MicroRNAs modulate VEGF expression by targeting HIF-1 $\alpha$ and STAT3 in MCF-7 breast cancer cells [120]. Sohn and colleagues found that overexpression of miRNA3195 and miRNA374b mimics in PC-3 cells reduced the mRNA levels of the angiogenesis-related proteins HIF- $1 \alpha$, HIF- $2 \alpha$ and VEGF under hypoxia, indicating that miRNA3195 and miRNA374b targeted the HIF-1/2 alpha/VEGF axis [101]. Melatonin upregulated miRNA3195 and miRNA374b as defined by miRNA microarray and qRT-PCR analysis. Overexpression of miRNA3195 and miRNA374b synergistically attenuated VEGF production by hypoxic PC-3 prostate cancer cells, indicating the critical role of miRNA3195 and miRNA374b in melatonin induced anti-angiogenic activity. Further investigation 
is warranted to verify the anti-angiogenic effects of miRNA3195 and miRNA374b in animals.

The study of Carbajo-Pescador and colleagues revealed a hypoxiadependent activation of VEGF transcriptional regulators, HIF-1 $\alpha$ and phospho-STAT3, which were suppressed by melatonin [23]. Antiangiogenic activity of melatonin in liver cancer cells may be mediated by inhibition of HIF-1 $\alpha$ nuclear translocation and subsequent VEGF expression [23]. In addition, results from other tumor types also demonstrated the capability of melatonin to regulate HIF-1 $\alpha$ activity $[33,35,36,95]$. Several studies reported that either HIF-1 $\alpha$ or STAT3 transcriptionally activated VEGF expression [121-124]. Other reports indicated that a maximal induction was achieved when both transcription factors bind to the VEGF promoter, where they were probably connected within the same transcriptional complex together with $\mathrm{CBP} / \mathrm{p} 300$ co-activator $[125,126]$. Carbajo-Pescador et al. demonstrated that HIF-1 $\alpha$ and STAT3 transcription factors promoted VEGF production in hypoxia-related angiogenesis in hepatocellular carcinoma [23]. Due to the lack of toxicity of melatonin even at high doses it is important to carry out further research to examine the effectiveness of this ubiquitously-acting indole for the treatment of patients with hepatocellular carcinoma $[23,80]$.

Kim and colleagues reported decreased protein level of HIF-1 $\alpha$ in the growing tumor masses taken from melatonin-treated mice, consistent with melatonin inhibition of HIF-1a during tumor progression [29]. Accordingly, the authors proposed that melatonin actually reduced HIFla through the scavenging of ROS produced during tumor progression. In this study as in many others, melatonin was well tolerated, without causing toxicity after long term administration necessary to achieve the therapeutic activities. These results provide an imperative rationale for the application of melatonin as an antineoplastic agent in clinical trials. Photons upregulated pro-angiogenic factors including VEGF, interleukin 6 (IL-6), HIF- $1 \alpha$ and basic fibroblast growth Factor (bFGF), resulting in enhanced angiogenesis and metastasis [103,104,127,128]. Girdhani and colleagues documented that proton irradiation significantly downregulated pro-angiogenic factors including VEGF, IL-6, IL-8 and HIF-1 $\alpha$ in human and murine cancer cells, and in human endothelial and fibroblast cells in vitro [109]. Exposure to carbon ion beam at the energy used in radiotherapy, a lower dose (10 cGy) of irradiation inhibited developing vessel models and cell migration using human endothelial cell line ECV304 cells [15]. Proton-irradiation of human lung adenocarcinoma cells (A549), human endothelial (HMVEC) and fibroblast (NHDF) cells downregulated the expression of pro-angiogenic factors including VEGF, IL-8, IL-6, and HIF-1 $\alpha$. On the contrary, photon irradiation of A549, HMVEC and NHDF cells upregulated these pro-angiogenic factors dose-dependently [109]. Boyd et al. confirmed that iris neovascularization in uveal melanomas was suppressed in proton-irradiated tissue concomitant with reduced VEGF protein expression compared to sham-irradiated controls [129]. A subsequent study also showed that protons at doses as low as $0.5 \mathrm{~Gy}$ inhibited developing vessels 3D in vitro culture models [128].

Tumor progression strongly depends on an angiogenic response [130-132]. Various factors are related to angiogenesis. MMP-2 and $\alpha \mathrm{V} \beta 3$ integrin are essential factors that play critical roles in angiogenesis $[15,133,134]$. In addition to angiogenesis, cancer cell invasion and migration are fundamental aspects of cancer progression that significantly contribute to metastasis. Ogata and colleagues found that low dose $(0.5 \mathrm{~Gy})$ photon irradiation promoted cell migration and invasion concomitant with up-regulation of $\alpha \mathrm{V} \beta 3$ integrin [106]. Carbon ion irradiation decreased cell migration and invasion in a dose-dependent manner and markedly inhibited MMP-2 activity. For cancer cells irradiated with carbon ion irradiation, the number of pulmonary metastases was decreased significantly. The study of Goetze and coworkers indicated that photon irradiation decreased HCT116 colon carcinoma cell migration at high doses and increased U87 glioma cell migration at 3 Gy or high doses [135]. Heavy ions limited migration of HCT116 colon carcinoma and U87 glioma cell lines dosedependently. The study of Akino and colleagues demonstrated that low dose photon irradiation stimulated cell proliferation of Non-Small-Cell Lung Cancer (NSCLC) cells [136]. Carbon beam irradiation reduced the migration and invasion capabilities of both A549 and EBC-1 cells more effectively than did photon irradiation. Carbon ion irradiation suppressed the metastatic potential of NSCLC cells. Stahler and colleagues claimed that 2 Gy photon irradiation increased migration of U87 EGFR ++ cells and decreased motility of LN229 EGFR ++ cells [137]. Heavy ions decreased migration of both cell lines. Photon beam radiation potentially contributed to treatment failure by increasing EGFR-related tumor cell migration. Carbon ion irradiation reduced the mobility of Glioblastoma Multiforme (GBM) cells lines. Heavy-ion irradiation may be more effective than conventional photon therapy in its possible effects for the inhibition of metastasis of irradiated malignant tumor cells [137]. These findings suggest that particle irradiation may inhibit processes of tumor progression (e.g., invasion, migration and angiogenesis) indispensable for metastasis. The results imply a potential for particle irradiation in the treatment of systemic disease. These well substantiated in vitro and in vivo findings provide preclinical evidence that particle irradiation may have uncommon biological relevance that can be employed for improving the therapeutic result during cancer treatment.

\section{Conclusion}

Angiogenesis plays an essential rolein tumor invasion and metastasis. Targeting the VEGF pathway could be a more effective strategy than targeting the tumor itself, based on the fact that angiogenesis is a major characteristic of solid tumors. Melatonin treatment effectively attenuates VEGF levels, mainly at pharmacological doses. Melatonin treatment decreased VEGF secretion by tumor cells. Hypoxia in tumors is a fundamental cause of angiogenesis. Under hypoxic conditions, melatonin inhibited HIF-1 transcriptional activity, resulting in reduction in VEGF expression. HIF- $1 \alpha$ is the essential transcription factor involved in regulation of angiogenesis in cancer. Melatonin suppressed the stability of HIF-1a. Melatonin also limited HIF-1a accumulation through inhibition of Sphingosine Kinase 1 (SPHK1) pathway and ROS generation in PC-3 cells under hypoxia. MicroRNAs (miRNAs) play essential roles in angiogenesis. Melatonin upregulated miRNA3195 and miRNA374b. Over-expression of miRNA3195 and miRNA374b synergistically attenuated VEGF production in hypoxic PC-3 cells, indicating the critical role of miRNA3195 and miRNA374b in melatonin-induced anti-angiogenic activity. Photons upregulates pro-angiogenic factors resulting in enhanced angiogenesis and metastasis. The capillary-like tube structures are abolished after $0.1 \mathrm{~Gy}$ carbon ion irradiation. Heavy ion irradiation could be more effective than X-ray irradiation in counteracting angiogenesis even at sublethal doses.

In addition to angiogenesis, cancer cell invasion and migration are fundamental aspects of cancer progression that significantly contribute to metastasis. Heavy ions decrease migration of HCT116 colon carcinoma and U87 glioma cell lines dose-dependently. Carbon beam irradiation reduces the migration and invasive capabilities of both A549 and EBC-1 cells more effectively than does photon irradiation. 
Carbon ion irradiation suppressed the metastatic potential of NonSmall-Cell Lung Cancer (NSCLC) cells. These results imply a potential for particle irradiation in the treatment of systemic disease. Further investigation to elucidate the mechanisms and molecular pathways involved in angiogenesis specifically associated with melatonin and charged particle irradiation certainly is warranted. Finally, considering the similar actions of melatonin and particle irradiation in terms of altering the process of angiogenesis in tumors, a combination therapy using these two modalities may be highly worthwhile.

\section{References}

1. Hicklin DJ, Ellis LM (2005) Role of the vascular endothelial growth factor pathway in tumor growth and angiogenesis. J Clin Oncol 23: 1011-1027. [crossref]

2. Tang N, Shi L, Yu Z, Dong P, Wang C, et al. (2016) Gamabufotalin, a major derivative of bufadienolide, inhibits VEGF-induced angiogenesis by suppressing VEGFR-2 signaling pathway. Oncotarget 7: 3533-3547. [crossref]

3. Kumaran G, Clamp AR, Jayson GC (2008) Angiogenesis as a therapeutic target in cancer. Clin Med (Lond) 8: 455-458. [crossref]

4. Zhao Y, Adjei AA (2015) Targeting Angiogenesis in Cancer Therapy: Moving Beyond Vascular Endothelial Growth Factor. Oncologist 20: 660-673. [crossref]

5. Folkman J1 (2007) Angiogenesis: an organizing principle for drug discovery? Nat Rev Drug Discov 6: 273-286. [crossref]

6. Wang Z, Wang N, Han S, Wang D, Mo S, et al. (2013) Dietary compound isoliquiritigenin inhibits breast cancer neoangiogenesis via VEGF/VEGFR-2 signaling pathway. PLoS One 8: e68566. [crossref]

7. Dvorak HF (2005) Angiogenesis: update 2005. J Thromb Haemost 3: 1835-1842. [crossref]

8. Ivy SP, Wick JY, Kaufman BM (2009) An overview of small-molecule inhibitors of VEGFR signaling. Nat Rev Clin Oncol 6: 569-579. [crossref]

9. Baskar R, Lee KA, Yeo R, Yeoh KW (2012) Cancer and radiation therapy: current advances and future directions. Int J Med Sci 9: 193-199. [crossref]

10. Su WH, Chuang PC, Huang EY, Yang KD (2012) Radiation-induced increase in cell migration and metastatic potential of cervical cancer cells operates via the K-Ras pathway. Am J Pathol 180: 862-871. [crossref]

11. Bert C, Engenhart-Cabillic R, Durante M (2012) Particle therapy for noncancer diseases. Med Phys 39: 1716-1727. [crossref]

12. Tsujii H, Kamada $\mathrm{T}$ (2012) A review of update clinical results of carbon ion radiotherapy. Jpn J Clin Oncol 42: 670-685. [crossref]

13. Helm A, Lee R, Durante M, Ritter S (2016) The Influence of C-Ions and X-rays on Human Umbilical Vein Endothelial Cells. Front Oncol 6: 5. [crossref]

14. Hamada N, Imaoka T, Masunaga S, Ogata T, Okayasu R, et al. (2010) Recent advances in the biology of heavy-ion cancer therapy. J Radiat Res 51: 365-383. [crossref]

15. Takahashi Y, Teshima T, Kawaguchi N, Hamada Y, Mori S, et al. (2003) Heavy ion irradiation inhibits in vitro angiogenesis even at sublethal dose. Cancer Res 63: 42534257. [crossref]

16. Cutando A, López-Valverde A, Arias-Santiago S, DE Vicente J, DE Diego RG (2012) Role of melatonin in cancer treatment. Anticancer Res 32: 2747-2753. [crossref]

17. Vijayalaxmi, Thomas CR Jr, Reiter RJ, Herman TS (2002) Melatonin: from basic research to cancer treatment clinics. J Clin Oncol 20: 2575-2601. [crossref]

18. Pariente R, Pariente JA, Rodríguez AB, Espino J (2016) Melatonin sensitizes human cervical cancer HeLa cells to cisplatin-induced cytotoxicity and apoptosis: effects on oxidative stress and DNA fragmentation. $J$ Pineal Res 60: 55-64. [crossref]

19. Sanchez-Barcelo EJ, Mediavilla MD, Alonso-Gonzalez C, Reiter RJ (2012) Melatonin uses in oncology: breast cancer prevention and reduction of the side effects of chemotherapy and radiation. Expert Opin Investig Drugs 21: 819-831. [crossref]

20. Reiter RJ, Tan DX, Galano A (2014) Melatonin: exceeding expectations. Physiology (Bethesda) 29: 325-333. [crossref]

21. Cabrera J, Negrín G, Estévez F, Loro J, Reiter RJ, et al. (2010) Melatonin decreases cell proliferation and induces melanogenesis in human melanoma SK-MEL-1 cells. $J$ Pineal Res 49: 45-54. [crossref]

22. Carbajo-Pescador S, García-Palomo A, Martín-Renedo J, Piva M, González-
Gallego J, et al. (2011) Melatonin modulation of intracellular signaling pathways in hepatocarcinoma HepG2 cell line: role of the MT1 receptor. J Pineal Res 51: 463-471. [crossref]

23. Carbajo-Pescador S, Ordonez R, Benet M, Jover R, Garcia-Palomo A, et al. (2013) Inhibition of VEGF expression through blockade of Hif1 $\mathrm{I} \pm$ and STAT3 signalling mediates the anti-angiogenic effect of melatonin in HepG2 liver cancer cells. $\mathrm{Br} J$ Cancer 109: 83-91. [crossref]

24. Wei JY, Li WM, Zhou LL, Lu QN, He W (2015) Melatonin induces apoptosis of colorectal cancer cells through HDAC4 nuclear import mediated by CaMKII inactivation. J Pineal Res 58: 429-438. [crossref]

25. Bizzarri M, Proietti S, Cucina A, Reiter RJ (2013) Molecular mechanisms of the proapoptotic actions of melatonin in cancer: a review. Expert Opin Ther Targets 17: 14831496. [crossref]

26. Manchester LC1, Coto-Montes A, Boga JA, Andersen LP, Zhou Z, et al. (2015) Melatonin: an ancient molecule that makes oxygen metabolically tolerable. $J$ Pineal Res 59: 403-419. [crossref]

27. Reiter RJ1, Mayo JC2, Tan DX2, Sainz RM2, Alatorre-Jimenez M2, et al. (2016) Melatonin as an antioxidant: under promises but over delivers. J Pineal Res 61: 253278. [crossref]

28. Zhang HM1, Zhang Y (2014) Melatonin: a well-documented antioxidant with conditional pro-oxidant actions. J Pineal Res 57: 131-146. [crossref]

29. Kim KJ, Choi JS, Kang I, Kim KW, Jeong CH, et al. (2013) Melatonin suppresses tumor progression by reducing angiogenesis stimulated by HIF-1 in a mouse tumor model. J Pineal Res 54: 264-270. [crossref]

30. Cui P1, Luo Z, Zhang H, Su Y, Li A, et al. (2006) Effect and mechanism of melatonin's action on the proliferation of human umbilical vein endothelial cells. J Pineal Res 41: 358-362. [crossref]

31. Lissoni P, Rovelli F, Malugani F, Bucovec R, Conti A, et al. (2001) Anti-angiogenic activity of melatonin in advanced cancer patients. Neuro Endocrinol Lett 22: 45-47. [crossref]

32. Lin YW, Lee LM, Lee WJ, et al. (2016) Melatonin inhibits MMP-9 transactivation and renal cell carcinoma metastasis by suppressing Akt-MAPKs pathway and NF-I ${ }^{\circ} \mathrm{B}$ DNA-binding activity. J Pineal Res 60: 277-290. [crossref]

33. Park SY, Jang WJ, Yi EY, Jang JY, Jung Y, et al. (2010) Melatonin suppresses tumor angiogenesis by inhibiting HIF-1alpha stabilization under hypoxia. J Pineal Res 48: 178-184. [crossref]

34. Cook KM, Figg WD (2010) Angiogenesis inhibitors: current strategies and future prospects. CA Cancer J Clin 60: 222-243. [crossref]

35. Dai M, Cui P, Yu M, Han J, Li H, et al. (2008) Melatonin modulates the expression of VEGF and HIF-1 alpha induced by $\mathrm{CoCl} 2$ in cultured cancer cells. J Pineal Res 44 : 121-126. [crossref]

36. Park JW, Hwang MS, Suh SI, Baek WK (2009) Melatonin down-regulates HIF-1 alpha expression through inhibition of protein translation in prostate cancer cells. J Pineal Res 46: 415-421. [crossref]

37. Alvarez-García V, González A, Alonso-González C, Martínez-Campa C, Cos S (2013) Antiangiogenic effects of melatonin in endothelial cell cultures. Microvasc Res 87: 25-33. [crossref]

38. Cui P, Yu M, Peng X, Dong L, Yang Z (2012) Melatonin prevents human pancreatic carcinoma cell PANC-1-induced human umbilical vein endothelial cell proliferation and migration by inhibiting vascular endothelial growth factor expression. $J$ Pineal Res 52: 236-243. [crossref]

39. Alvarez-García V, González A, Alonso-González C, Martínez-Campa C, Cos S (2013) Regulation of vascular endothelial growth factor by melatonin in human breast cancer cells. J Pineal Res 54: 373-380. [crossref]

40. Tanaka S, Arii S (2006) Current status and perspective of antiangiogenic therapy for cancer: hepatocellular carcinoma. Int J Clin Oncol 11: 82-89. [crossref]

41. Wu XZ, Xie GR, Chen D (2007) Hypoxia and hepatocellular carcinoma: The therapeutic target for hepatocellular carcinoma. J Gastroenterol Hepatol 22: 1178-1182. [crossref]

42. Dong ZZ, Yao M, Wang L, Wu W, Gu X, et al. (2013) Hypoxia-inducible factor-1alpha: molecular-targeted therapy for hepatocellular carcinoma. Mini Rev Med Chem 13: 1295-1304. [crossref]

43. Pang R, Poon RT (2006) Angiogenesis and antiangiogenic therapy in hepatocellular carcinoma. Cancer Lett 242: 151-167. [crossref] 
44. Kaseb AO, Hanbali A, Cotant M, Hassan MM, Wollner I, et al. (2009) Vascular endothelial growth factor in the management of hepatocellular carcinoma: a review of literature. Cancer 115: 4895-4906. [crossref]

45. Kaseb AO, Morris JS, Hassan MM, Siddiqui AM, Lin E, et al. (2011) Clinical and prognostic implications of plasma insulin-like growth factor-1 and vascular endothelia growth factor in patients with hepatocellular carcinoma. J Clin Oncol 29: 3892-3899. [crossref]

46. Sun HC, Tang ZY (2004) Angiogenesis in hepatocellular carcinoma: the retrospectives and perspectives. J Cancer Res Clin Oncol 130: 307-319. [crossref]

47. Niu G, Briggs J, Deng J, Ma Y, Lee H, et al. (2008) Signal transducer and activator of transcription 3 is required for hypoxia-inducible factor-1alpha RNA expression in both tumor cells and tumor-associated myeloid cells. Mol Cancer Res 6: 1099-1105. [crossref]

48. Chen H, Guan Y, Yuan G, Zhang Q, Jing N (2014) A perylene derivative regulates HIF-1 $1 \pm$ and Stat3 signaling pathways. Bioorg Med Chem 22: 1496-1505. [crossref]

49. Saif MW (2006) Anti-angiogenesis therapy in pancreatic carcinoma. JOP 7: 163-173. [crossref]

50. Longo R, Cacciamani F, Naso G, Gasparini G (2008) Pancreatic cancer: from molecular signature to target therapy. Crit Rev Oncol Hematol 68: 197-211. [crossref]

51. Cao N, Cao M, Chin-Sinex H, Mendonca M, Ko SC, et al. (2014) Monitoring the effects of anti-angiogenesis on the radiation sensitivity of pancreatic cancer xenografts using dynamic contrast-enhanced computed tomography. Int J Radiat Oncol Biol Phys 88: 412-418. [crossref]

52. Lv D, Cui PL, Yao SW, Xu YQ, Yang ZX (2012) Melatonin inhibits the expression of vascular endothelial growth factor in pancreatic cancer cells. Chin J Cancer Res 24 310-316. [crossref]

53. Lanzer M, Gander T, Kruse A, Luebbers HT, Reinisch S (2014) Influence of histopathologic factors on pattern of metastasis in squamous cell carcinoma of the head and neck. Laryngoscope 124: E160-166. [crossref]

54. Sakamoto Y, Matsushita Y, Yamada S, Yanamoto S, Shiraishi T, et al. (2016) Risk factors of distant metastasis in patients with squamous cell carcinoma of the oral cavity. Oral Surg Oral Med Oral Pathol Oral Radiol 121: 474-480. [crossref]

55. Islam M, Sharma S, Kumar B, Teknos TN (2013) Atorvastatin inhibits RhoC function and limits head and neck cancer metastasis. Oral Oncol 49: 778-786. [crossref]

56. Liang X, Yang D, Hu J, Hao X, Gao J, et al. (2008) Hypoxia inducible factor-alpha expression correlates with vascular endothelial growth factor-C expression and lymphangiogenesis/angiogenesis in oral squamous cell carcinoma. Anticancer Res 28: 1659-1666. [crossref]

57. Yanase M, Kato K, Yoshizawa K, Noguchi N, Kitahara H, et al. (2014) Prognostic value of vascular endothelial growth factors $\mathrm{A}$ and $\mathrm{C}$ in oral squamous cell carcinoma. J Oral Pathol Med 43: 514-520. [crossref]

58. Andisheh-Tadbir A, Mardani M, Pourshahidi S, Nezarati K, Bahadori P (2016) Prognostic value of matrix metalloproteinase-9 expression in oral squamous cell carcinoma and its association with angiogenesis. J Clin Exp Dent 8: e130-135. [crossref]

59. Eckert AW, Kappler M, Schubert J, Taubert H (2012) Correlation of expression of hypoxia-related proteins with prognosis in oral squamous cell carcinoma patients. Oral Maxillofac Surg 16: 189-196. [crossref]

60. Goncalves Ndo N, Rodrigues RV, Jardim-Perassi BV, Moschetta MG, Lopes JR, et al. (2014) Molecular markers of angiogenesis and metastasis in lines of oral carcinoma after treatment with melatonin. Anticancer Agents Med Chem 14: 1302-1311. [crossref]

61. Ichihara E, Kiura K, Tanimoto M (2011) Targeting angiogenesis in cancer therapy. Acta Med Okayama 65: 353-362. [crossref]

62. Weis SM1, Cheresh DA (2011) Tumor angiogenesis: molecular pathways and therapeutic targets. Nat Med 17: 1359-1370. [crossref]

63. Masoud GN, Li W (2015) HIF-1 $\alpha$ pathway: role, regulation and intervention for cancer therapy. Acta Pharm Sin B 5: 378-389. [crossref]

64. Qian J, Bai H, Gao Z, Dong YU, Pei J, et al. (2016) Downregulation of HIF-1 1 I \pm inhibits the proliferation and invasion of non-small cell lung cancer NCI-H157 cells. Oncol Let 11: 1738-1744. [crossref]

65. Kallergi G, Markomanolaki H, Giannoukaraki V, Papadaki MA, Strati A, et al. (2009) Hypoxia-inducible factor-1alpha and vascular endothelial growth factor expression in circulating tumor cells of breast cancer patients. Breast Cancer Res 11: R84. [crossref]

66. Petit I, Jin D, Rafii S (2007) The SDF-1-CXCR4 signaling pathway: a molecular hub modulating neo-angiogenesis. Trends Immunol 28: 299-307. [crossref]

67. Jin DK, Shido K, Kopp HG, Petit I, Shmelkov SV, et al. (2006) Cytokine-mediated deployment of SDF-1 induces revascularization through recruitment of CXCR4+ hemangiocytes. Nat Med 12: 557-567. [crossref]

68. Xin Z, Jiang S, Jiang P, Yan X, Fan C, et al. (2015) Melatonin as a treatment for gastrointestinal cancer: a review. J Pineal Res 58: 375-387. [crossref]

69. Jardim-Perassi BV, Lourenço MR, Doho GM, Grígolo IH, Gelaleti GB, et al. (2016) Melatonin Regulates Angiogenic Factors under Hypoxia in Breast Cancer Cell Lines. Anticancer Agents Med Chem 16: 347-358. [crossref]

70. Wang RX, Liu H, Xu L, Zhang H, Zhou RX (2015) Involvement of nuclear receptor RZR/ROR $\hat{I}^{3}$ in melatonin-induced HIF-1 $\hat{\mathrm{I}} \pm$ inactivation in SGC-7901 human gastric cancer cells. Oncol Rep 34: 2541-2546. [crossref]

71. Zhang Y, Liu Q, Wang F, Ling EA, Liu S, et al. (2013) Melatonin antagonizes hypoxiamediated glioblastoma cell migration and invasion via inhibition of HIF-1 $1 \hat{\mathrm{I}} \pm$. J Pineal Res 55: 121-130. [crossref]

72. Reiter RJ (2004) Mechanisms of cancer inhibition by melatonin. J Pineal Res 37: 213 214. [crossref]

73. Reiter RJ, Tan DX, Korkmaz A, Erren TC, Piekarski C, et al. (2007) Light at night, chronodisruption, melatonin suppression, and cancer risk: a review. Crit Rev Oncog 13: 303-328. [crossref]

74. Hill SM, Belancio VP, Dauchy RT, Xiang S, Brimer S, et al. (2015) Melatonin: an inhibitor of breast cancer. Endocr Relat Cancer 22: R183-204. [crossref]

75. Proietti S, Cucina A, Reiter RJ, Bizzarri M (2013) Molecular mechanisms of melatonin's inhibitory actions on breast cancers. Cell Mol Life Sci 70: 2139-2157. [crossref]

76. Ma Z, Yang Y, Fan C, Han J, et al. (2016) Melatonin as a potential anticarcinogen for non-small-cell lung cancer. Oncotarget . [crossref]

77. Borin TF, Arbab AS, Gelaleti GB, Ferreira LC, et al. (2016) Melatonin decreases breast cancer metastasis by modulating Rho-associated kinase protein-1 expression. J Pineal Res 60: 3-15. [crossref]

78. Vriend J, Reiter RJ (2015) Breast cancer cells: Modulation by melatonin and the ubiquitin-proteasome system--a review. Mol Cell Endocrinol 417: 1-9. [crossref]

79. Sanchez-Barcelo EJ, Mediavilla MD, Vriend J, Reiter RJ (2016) Constitutive photomorphogenesis protein 1 (COP1) and COP9 signalosome, evolutionarily conserved photomorphogenic proteins as possible targets of melatonin. J Pineal Res 61: 41-51. [crossref]

80. Hevia D, Gonzalez-Mendez P, Quiros-Gonzales I, Miar A, Rodriguez-Garcia A, et al. (2015) Melatonin uptake through glucose transporters: a new target for melatonin inhibition of cancer. J Pineal Res 58: 234-250. [crossref]

81. Jardim-Perassi BV, Arbab AS, Ferreira LC, Borin TF, Varma NR, et al. (2014) Effect of melatonin on tumor growth and angiogenesis in xenograft model of breast cancer. PLoS One 9: e85311. [crossref]

82. Ulivi P, Marisi G, Passardi A (2016) Relationship between hypoxia and response to antiangiogenic therapy in metastatic colorectal cancer. Oncotarget . [crossref]

83. Kaur C, Sivakumar V, Lu J, Tang FR, Ling EA (2008) Melatonin attenuates hypoxiainduced ultrastructural changes and increased vascular permeability in the developing hippocampus. Brain Pathol 18: 533-547. [crossref]

84. Andersen LP, Gögenur I, Rosenberg J, Reiter RJ (2016) Pharmacokinetics of Melatonin The Missing Link in Clinical Efficacy? Clin Pharmacokinet 55: 1027-1030. [crossref]

85. Reiter RJ, Tan DX, Sainz RM, Mayo JC, Lopez-Burillo S (2002) Melatonin: reducing the toxicity and increasing the efficacy of drugs. J Pharm Pharmacol 54: 1299-1321. [crossref]

86. Alonso-González C, González A, Martínez-Campa C, Gómez-Arozamena J, Cos S (2015) Melatonin sensitizes human breast cancer cells to ionizing radiation by downregulating proteins involved in double-strand DNA break repair. J Pineal Res 58: 189-197. [crossref]

87. Xiang S, Dauchy RT (2015) Doxorubicin resistance in breast cancer is driven by light at night-induced disruption of the circadian melatonin signal. J Pineal Res 59: 60-69. [crossref]

88. Fan C, Pan Y, Yang Y, Di S, Jiang S, et al. (2015) HDAC1 inhibition by melatonin leads to suppression of lung adenocarcinoma cells via induction of oxidative stress and activation of apoptotic pathways. J Pineal Res 59: 321-333. [crossref]

89. Park SY, Jang WJ, Yi EY, Jang JY, Jung Y, et al. (2010) Melatonin suppresses tumor 
angiogenesis by inhibiting HIF-1alpha stabilization under hypoxia. $J$ Pineal Res 48 : 178-184. [crossref]

90. McDonald PC, Chafe SC, Dedhar S (2016) Overcoming Hypoxia-Mediated Tumor Progression: Combinatorial Approaches Targeting $\mathrm{pH}$ Regulation, Angiogenesis and Immune Dysfunction. Front Cell Dev Biol 4: 27. [crossref]

91. Lin D, Wu J (2015) Hypoxia inducible factor in hepatocellular carcinoma: A therapeutic target. World J Gastroenterol 21: 12171-12178. [crossref]

92. Reiter RJ, Tan DX, Korkmaz A, Manchester LC (2011) The disaster in Japan: utility of melatonin in providing protection against ionizing radiation. J Pineal Res 50: 357358. [crossref]

93. Cho SY, Lee HJ, Jeong SJ, Lee HJ, Kim HS, et al. (2011) Sphingosine kinase 1 pathway is involved in melatonin-induced HIF-1 $\mathrm{I} \pm$ inactivation in hypoxic $\mathrm{PC}-3$ prostate cancer cells. J Pineal Res 51: 87-93. [crossref]

94. Leja-Szpak A, Jaworek J, Pierzchalski P, Reiter RJ (2010) Melatonin induces proapoptotic signaling pathway in human pancreatic carcinoma cells (PANC-1). $J$ Pineal Res 49: 248-255. [crossref]

95. Harris AL (2002) Hypoxia--a key regulatory factor in tumour growth. Nat Rev Cancer 2: 38-47. [crossref]

96. Semenza GL (2001) HIF-1, O(2), and the 3 PHDs: how animal cells signal hypoxia to the nucleus. Cell 107: 1-3. [crossref]

97. Yang L, Zheng J, Xu R, Zhang Y, Gu L, et al. (2014) Melatonin suppresses hypoxiainduced migration of HUVECs via inhibition of ERK/Rac1 activation. Int J Mol Sci 15: 14102-14121. [crossref]

98. Bartel DP (2004) MicroRNAs: genomics, biogenesis, mechanism, and function. Cell 116: 281-297. [crossref]

99. Schickel R, Boyerinas B, Park SM, Peter ME (2008) MicroRNAs: key players in the immune system, differentiation, tumorigenesis and cell death. Oncogene 27: 59595974. [crossref]

100. Finn NA, Searles CD (2012) Intracellular and Extracellular miRNAs in Regulation of Angiogenesis Signaling. Curr Angiogenes 4: 299-307. [crossref]

101. Sohn EJ, Won G, Lee J, Lee S, Kim SH (2015) Upregulation of miRNA3195 and miRNA374b Mediates the Anti-Angiogenic Properties of Melatonin in Hypoxic PC-3 Prostate Cancer Cells. J Cancer 6: 19-28. [crossref]

102. Moeller BJ, Cao Y, Li CY, Dewhirst MW (2004) Radiation activates HIF-1 to regulate vascular radiosensitivity in tumors: role of reoxygenation, free radicals, and stress granules. Cancer Cell 5: 429-441. [crossref]

103. Sofia Vala I, Martins LR, Imaizumi N, Nunes RJ, Rino J, et al. (2010) Low doses of ionizing radiation promote tumor growth and metastasis by enhancing angiogenesis. PLoS One 5: e11222. [crossref]

104. Sonveaux P, Brouet A, Havaux X, Grégoire V, Dessy C, et al. (2003) Irradiationinduced angiogenesis through the up-regulation of the nitric oxide pathway: implications for tumor radiotherapy. Cancer Res 63: 1012-1019. [crossref]

105. Kamlah F, Hänze J, Arenz A, Seay U, Hasan D, et al. (2011) Comparison of the effects of carbon ion and photon irradiation on the angiogenic response in human lung adenocarcinoma cells. Int J Radiat Oncol Biol Phys 80: 1541-1549. [crossref]

106. Ogata T, Teshima T, Kagawa K, Hishikawa Y, Takahashi Y, et al. (2005) Particle irradiation suppresses metastatic potential of cancer cells. Cancer Res 65: 113-120. [crossref]

107. Liu Y, Liu Y, Zhang H, Sun C, Zhao Q, et al. (2014) Effects of carbon-ion beam irradiation on the angiogenic response in lung adenocarcinoma A549 cells. Cell Biol Int 38: 1304-1310. [crossref]

108. Liu Y, Liu Y, Sun C, Gan L, Zhang L, et al. (2014) Carbon ion radiation inhibits glioma and endothelial cell migration induced by secreted VEGF. PLoS One 9: e98448. [crossref]

109. Girdhani S, Lamont C, Hahnfeldt P, Abdollahi A, Hlatky L (2012) Proton irradiation suppresses angiogenic genes and impairs cell invasion and tumor growth. Radiat Res 178: 33-45. [crossref]

110. Chand R, Chandra H, Chandra S, Verma SK (2016) Role of Microvessel Density and Vascular Endothelial Growth Factor in Angiogenesis of Hematological Malignancies. Bone Marrow Res 2016: 5043483. [crossref]

111. Zhao Y, Adjei AA (2015) Targeting Angiogenesis in Cancer Therapy: Moving Beyond Vascular Endothelial Growth Factor. Oncologist 20: 660-673. [crossref]
112. Ciardiello F, Troiani T, Bianco R, Orditura M, Morgillo F, et al. (2006) Interaction between the epidermal growth factor receptor (EGFR) and the vascular endothelial growth factor (VEGF) pathways: a rational approach for multi-target anticancer therapy. Ann Oncol 17 Suppl 7:vii109-114. [crossref]

113. Tabernero J (2007) The role of VEGF and EGFR inhibition: implications for combining anti-VEGF and anti-EGFR agents. Mol Cancer Res 5: 203-220. [crossref]

114. Bianco R, Rosa R, Damiano V, Daniele G, Gelardi T, et al. (2008) Vascular endothelia growth factor receptor-1 contributes to resistance to anti-epidermal growth factor receptor drugs in human cancer cells. Clin Cancer Res 14: 5069-5080. [crossref]

115. Qian J, Bai H, Gao Z, Dong YU, Pei J, et al. (2016) Downregulation of HIF-1 $\mathrm{I} \pm$ inhibits the proliferation and invasion of non-small cell lung cancer NCI-H157 cells. Oncol Lett 11: 1738-1744. [crossref]

116. Ferrara N (2004) Vascular endothelial growth factor: basic science and clinical progress. Endocr Rev 25: 581-611. [crossref]

117. Hong L, Han Y, Zhou Y, Nita A (2013) Angiogenesis-related microRNAs in colon cancer. Expert Opin Biol Ther 13: 77-84. [crossref]

118. Madanecki P, Kapoor N, Bebok Z, Ochocka R, Collawn JF, et al. (2013) Regulation of angiogenesis by hypoxia: the role of microRNA. Cell Mol Biol Lett 18: 47-57. [crossref]

119. Hua Z, Lv Q, Ye W, Wong CK, Cai G, et al. (2006) MiRNA-directed regulation of VEGF and other angiogenic factors under hypoxia. PLoS One 1: e116. [crossref]

120. Cascio S, D'Andrea A, Ferla R, Surmacz E, Gulotta E, et al. (2010) miR-20b modulates VEGF expression by targeting HIF-1 alpha and STAT3 in MCF-7 breast cancer cells. J Cell Physiol 224: 242-249. [crossref]

121. Riddell JR, Maier P, Sass SN, Moser MT, Foster BA, et al. (2012) Peroxiredoxin 1 stimulates endothelial cell expression of VEGF via TLR4 dependent activation of HIF-1 $1 \hat{\mathrm{I}} \pm$. PLoS One 7: e50394. [crossref]

122. Shen K, Ji L, Gong C, Ma Y, Yang L, et al. (2012) Notoginsenoside Ft1 promotes angiogenesis via HIF- $1 \alpha$ mediated VEGF secretion and the regulation of PI3K/AKT and Raf/MEK/ERK signaling pathways. Biochem Pharmacol 84: 784-792. [crossref]

123. Zeng D, Wang J, Kong P, Chang C, Li J, et al. (2014) Ginsenoside Rg3 inhibits HIF$1 \alpha$ and VEGF expression in patient with acute leukemia via inhibiting the activation of PI3K/Akt and ERK1/2 pathways. Int J Clin Exp Pathol 7: 2172-2178. [crossref]

124. Matsumura A, Kubota T, Taiyoh H, Fujiwara H, Okamoto K, et al. (2013) HGF regulates VEGF expression via the c-Met receptor downstream pathways, PI3K/Akt, MAPK and STAT3, in CT26 murine cells. Int J Oncol 42: 535-542. [crossref]

125. Jung JE, Lee HG, Cho IH, Chung DH, Yoon SH, et al. (2005) STAT3 is a potential modulator of HIF-1-mediated VEGF expression in human renal carcinoma cells FASEB J 19: 1296-1298. [crossref]

126. Rathinavelu A, Narasimhan M, Muthumani P (2012) A novel regulation of VEGF expression by HIF-1 $\mathrm{I} \pm$ and STAT3 in HDM2 transfected prostate cancer cells. $J$ Cell Mol Med 16: 1750-1757. [crossref]

127. Park CM, Park MJ, Kwak HJ, Lee HC, Kim MS, et al. (2006) Ionizing radiation enhances matrix metalloproteinase- 2 secretion and invasion of glioma cells through Src/epidermal growth factor receptor-mediated p38/Akt and phosphatidylinositol 3-kinase/Akt signaling pathways. Cancer Res 66: 8511-8519. [crossref]

128. Grabham P, Hu B, Sharma P, Geard C (2011) Effects of ionizing radiation on threedimensional human vessel models: differential effects according to radiation quality and cellular development. Radiat Res 175: 21-28. [crossref]

129. Boyd SR, Gittos A, Richter M, Hungerford JL, Errington RD, et al. (2006) Proton beam therapy and iris neovascularisation in uveal melanoma. Eye (Lond) 20: 832-836. [crossref]

130. Geng L, Donnelly E, McMahon G, Lin PC, Sierra-Rivera E, et al. (2001) Inhibition of vascular endothelial growth factor receptor signaling leads to reversal of tumor resistance to radiotherapy. Cancer Res 61: 2413-2419. [crossref]

131. McMahon G (2000) VEGF receptor signaling in tumor angiogenesis. Oncologist 5 Suppl 1: 3-10. [crossref]

132. Konda B, Shum H, Rajdev L (2015) Anti-angiogenic agents in metastatic colorectal cancer. World J Gastrointest Oncol 7: 71-86. [crossref]

133. Bello L, Francolini M, Marthyn P, Zhang J, Carroll RS, et al. (2001) Alpha(v)beta3 and alpha(v)beta5 integrin expression in glioma periphery. Neurosurgery 49: 380-389. [crossref]

134. Silletti S, Kessler T, Goldberg J, Boger DL, Cheresh DA (2001) Disruption of matrix 
metalloproteinase 2 binding to integrin alpha vbeta 3 by an organic molecule inhibits angiogenesis and tumor growth in vivo. Proc Natl Acad Sci U S A 98: 119-124. [crossref]

135. Goetze K, Scholz M, Taucher-Scholz G, Mueller-Klieser W (2007) The impact of conventional and heavy ion irradiation on tumor cell migration in vitro. Int $J$ Radiat Biol 83: 889-896. [crossref]
136. Akino Y, Teshima T, Kihara A, Kodera-Suzumoto Y, Inaoka M, et al. (2009) Carbonion beam irradiation effectively suppresses migration and invasion of human nonsmall-cell lung cancer cells. Int J Radiat Oncol Biol Phys 75: 475-481. [crossref]

137. Stahler C, Roth J, Cordes N, Taucher-Scholz G, Mueller-Klieser W (2013) Impact of carbon ion irradiation on epidermal growth factor receptor signaling and glioma cell migration in comparison to conventional photon irradiation. Int J Radiat Biol 89: 454-461. [crossref

Copyright: C2016 Liu MT. This is an open-access article distributed under the terms of the Creative Commons Attribution License, which permits unrestricted use, distribution, and reproduction in any medium, provided the original author and source are credited. 